\title{
MicroRNA deregulation in human thyroid papillary carcinomas
}

\author{
$P$ Pallante ${ }^{* 1,2}, R$ Visone $^{* 1,3}$, M Ferracin $^{4}$, A Ferraro $^{2}, M$ T Berlingieri $^{1}$, \\ G Troncone $^{2,5}$, G Chiappetta $^{6}, C$ G Liu $^{3}$, M Santoro $^{1,2}$, M Negrini $^{4}$, C M Croce $^{3}$ \\ and $A$ Fusco $^{1,2}$
}

\footnotetext{
${ }^{1}$ Dipartimento di Biologia e Patologia Cellulare e Molecolare, c/o Istituto di Endocrinologia ed Oncologia Sperimentale del CNR, Facoltà di Medicina e Chirurgia, Università degli Studi di Napoli 'Federico II', via Pansini, 5, 80131 Naples, Italy

${ }^{2}$ NOGEC (Naples Oncogenomic Center)-CEINGE, Biotecnologie Avanzate-Napoli and SEMM - European School of Molecular Medicine - Naples Site, via Comunale Margherita, 482, 80145 Naples, Italy

${ }^{3}$ Division of Human Cancer Genetics, Comprehensive Cancer Center, Ohio State University, 410 West 12th Avenue, Columbus, Ohio 43210, USA

${ }^{4}$ Dipartimento di Medicina Sperimentale e Diagnostica, e Centro Interdipartimentale per la Ricerca sul Cancro, 44100 Ferrara, Italy

${ }^{5}$ Dipartimento di Anatomia Patologica e Citopatologia, Facoltà di Medicina e Chirurgia, Università degli Studi di Napoli 'Federico II', via Pansini, 5, 80131 Naples, Italy

${ }^{6}$ Istituto Nazionale dei Tumori, Fondazione Pascale, via Mariano Semmola, 80131 Naples, Italy
}

(Requests for offprints should be addressed to A Fusco; Email: afusco@ napoli.com or C M Croce; Email: carlo.croce@ osumc.edu) *(P Pallante and R Visone contributed equally to this work)

\begin{abstract}
MicroRNAs (miRNAs) are a class of small non-coding RNAs involved in a wide range of basic processes such as cell proliferation, development, apoptosis and stress response. It has recently been found that they are also abnormally expressed in many types of human cancer. We analyzed the genome-wide miRNA expression profile in human thyroid papillary carcinomas (PTCs) using a microarray (miRNACHIP microarray) containing hundreds of human precursor and mature miRNA oligonucleotide probes. Using this approach, we found an aberrant miRNA expression profile that clearly differentiates PTCs from normal thyroid tissues. In particular, a significant increase in miRNA (miR)-221, -222 and -181b was detected in PTCs in comparison with normal thyroid tissue. These results were further confirmed by northern blot and quantitative RT-PCR analyses. Moreover, RT-PCR revealed miR-221, -222 and $-181 \mathrm{~b}$ overexpression in fine needle aspiration biopsies corresponding to thyroid nodules, which were eventually diagnosed as papillary carcinomas after surgery. Finally, miR-221, -222 and $-181 \mathrm{~b}$ overexpression was also demonstrated in transformed rat thyroid cell lines and in mouse models of thyroid carcinogenesis. Functional studies, performed by blocking miR-221 function and by overexpressing miR-221 in human PTC-derived cell lines, suggest a critical role of miR-221 overexpression in thyroid carcinogenesis. In conclusion, these data, taken together, indicate an miRNA signature associated with PTCs, and suggest miRNA deregulation as an important event in thyroid cell transformation.
\end{abstract}

Endocrine-Related Cancer (2006) 13 497-508

\section{Introduction}

MicroRNAs (miRNAs) represent a class of endogenous, small, non-coding but functional RNAs of 19-23 nt cleaved from larger hairpin precursors (Bartel 2004). They comprise one of the most abundant classes of gene regulatory molecules in multicellular organism and likely influence the output of many protein-coding genes (Bartel 2004).
In fact, they are able to bind to the $3^{\prime}$-untranslated region (UTR) of target mRNAs and cause a block of translation or mRNA degradation (Rhoades et al. 2002, Tang et al. 2003, Ambros 2004, Bartel 2004). They are also functional when positioned in a coding region or even in $5^{\prime}$-UTR (Pillai 2005). The miRNA expression pattern is regulated during development and is generally tissue specific (Liu et al. 2004, Sempere et al. 2004). However, relatively 
little is known about their possible functions in mammalians.

At the present time, there are several reports indicating that miRNAs also represent a class of genes involved in human tumorigenesis, being aberrantly expressed, deleted, amplified or mutated in cancers (Calin et al. 2002, 2004a,b, 2005, McManus 2003, Michael et al. 2003, Metzler et al. 2004, Takamizawa et al. 2004, Eis et al. 2005, Gregory \& Shiekhattar 2005, Johnson et al. 2005). Deregulated expression of certain miRNAs has been linked to human proliferative diseases such as B-cell chronic lymphocytic leukemia (Calin et al. 2002, Lagos-Quintana et al. 2003), breast (Iorio et al. 2005) and colorectal neoplasia (Michael et al. 2003), suggesting that they might play a role as oncogenes or tumor suppressors. Moreover, it has recently become possible to analyze the genome-wide miRNA expression thanks to the development of microarrays containing sequences corresponding to all known human miRNAs (Liu et al. 2004, Nelson et al. 2004, Liang et al. 2005). Therefore, these miRNA microarrays can allow the identification of miRNAs differentially expressed between normal and tumor samples.

Thyroid neoplasms represent a good model for studying the events involved in epithelial cell multistep carcinogenesis, because they comprise a broad spectrum of lesions with different degrees of malignancy from benign adenomas, which are not invasive and very well differentiated, to the undifferentiated anaplastic thyroid carcinomas, which are very aggressive and always fatal. Papillary and follicular carcinomas, the most common forms of thyroid cancer, represent intermediate forms of neoplasia being differentiated and having a good prognosis (Hedinger et al. 1989, Wynford-Thomas 1997).

In this study, we have analyzed the genome-wide miRNA expression profile in 30 human papillary thyroid carcinoma (PTC) samples vs 10 normal thyroid tissue samples using a microarray containing oligonucleotide probes corresponding to 245 human precursors and mature miRNAs (miRNACHIP microarray; see Materials and methods). A subset of miRNAs was found to be overexpressed in PTC samples. In particular, miRNA (miR)-221, -222 and $-181 \mathrm{~b}$ were overexpressed in most of the PTCs analyzed, and also in fine needle aspiration biopsies (FNABs) originating from patients affected by PTC. Blocking miR-221 function by antisense methodology led to a reduced cell growth of a human PTC cell line, while its overexpression led to increased colony formation, indicating a critical role of miR-221 overexpression in thyroid carcinogenesis.

\section{Materials and methods}

\section{Thyroid tissue samples}

Human neoplastic thyroid tissues and normal adjacent tissue or the controlateral normal thyroid lobe were obtained from surgical specimens and immediately frozen in liquid nitrogen. Thyroid tumors were collected at the Service d'AnatomoPathologie, Centre Hospitalier Lyon Sud, Pierre Benite, France. RNA from 10 normal thyroid samples and 30 samples from patients with PTC were assessed for miRNA expression.

\section{FNAB}

The FNABs were performed at the Dipartimento di Anatomia Patologica e Citopatologia, Naples as described elsewhere (Zeppa et al. 1990, Troncone et al. 2000). Samples were obtained from eight patients with thyroid neoplasias who subsequently underwent surgery because examination of the FNAB yielded cytologic diagnoses suspicious for cancer. Normal thyroid cells, used as controls, were obtained from FNABs of thyroids carrying non-neoplastic nodules. FNAB samples were washed twice with $1 \times$ PBS and then processed for RNA extraction following the same procedure as that outlined below.

\section{RNA extraction}

Total RNA isolation was performed with Trizol (Invitrogen, Carlsbad, CA, USA) according to the manufacturer's instructions. RNA was extracted from fresh specimens after pulverizing the tumors in a stainless steel mortar and pestle that were chilled on dry ice. The integrity of the RNA was assessed by denaturing agarose gel electrophoresis.

\section{miRNACHIP microarray}

Microarray experimental procedures were performed as previously described (Liu et al. 2004). Briefly, labeled targets from $5 \mu \mathrm{g}$ total RNA from each sample were biotin-labeled during reverse transcription using random examers. Hybridization was carried out on an miRNA microarray chip (KCI version 1.0 (Liu et al. 2004)) containing 368 probes in triplicate, corresponding to 245 human and mouse miRNA genes. Hybridization signals were 
detected by biotin binding of a streptavidin-alexa 647 conjugate using a Perkin-Elmer ScanArray XL5K (Perkin-Elmer, Wellesley, MA, USA). Scanner images were quantified by the Quantarray software (Perkin-Elmer). Raw data were normalized and analyzed by GENESPRING software, version 7.2 (Silicon Genetics, Redwood City, CA, USA). Expression data were median centered by using the GENESPRING normalization option. Statistical comparisons were done with the GENESPRING ANOVA tool.

\section{Northern blot analysis}

This was carried out as described previously (Calin et al. 2002). RNA samples (10 $\mu \mathrm{g}$ each) were electrophoresed on $15 \%$ acrylamide, $7 \mathrm{~mol} / 1$ urea Criterion precasted gels (Bio-Rad, Hercules, CA, USA) and transferred onto Hybond- $\mathrm{N}^{+}$membrane (Amersham Biosciences, Piscataway, NJ, USA). Hybridization was performed at $37^{\circ} \mathrm{C}$ in $7 \% \quad \mathrm{SDS} / 0.2 \mathrm{~mol} / 1$ $\mathrm{Na}_{2} \mathrm{PO}_{4}(\mathrm{pH}$ 7.0) for $16 \mathrm{~h}$. Membranes were washed at $42{ }^{\circ} \mathrm{C}$, twice with $2 \times$ standard saline phosphate $(0.18 \mathrm{~mol} / 1 \mathrm{NaCl} / 10 \mathrm{mmol} / 1$ phosphate $(\mathrm{pH} 7.4)$ ), $1 \mathrm{mmol} / 1$ EDTA (saline-sodium phosphate-EDTA; SSPE) and $0.1 \%$ SDS and twice with $0.5 \times \mathrm{SSPE} /$ $0.1 \% \mathrm{SDS}$. The oligonucleotides used as probes, complementary to the sequences of the mature miRNAs, were as follows. miR-221-probe 5'-GAAACCCAGCAGACAATGTAGCT-3' ${ }^{\prime}$ miR-222-probe $5^{\prime}$-GAGACCCAGTAGCCAGATGTAGCT-3'; miR-181bprobe $5^{\prime}$-CCCACCGACAGCAATGAATGTT-3'.

An oligonucleotide complementary to the U6 RNA (5'-GCAGGGGCCATGCTAATCTTCTCTGTATCG-3') was used to normalize expression levels. Totally $200 \mathrm{ng}$ of each probe were end labeled with $100 \mathrm{mCi}\left[\gamma-{ }^{32} \mathrm{P}\right] \mathrm{ATP}$ using the polynucleotide kinase (Roche, Basel, Switzerland). Blots were stripped by boiling in $0.1 \%$ SDS for 10 min before re-hybridization and were successfully re-probed up to three times.

\section{Quantitative RT-PCR for miRNA precursors}

Quantitative RT-PCR was performed as described by Schmittgen et al. (2004). Briefly, RNA was reverse transcribed to cDNA with gene-specific primers and Thermoscript (Invitrogen), and the relative amount of each miRNA was normalized to the U6 RNA using the equation $2^{-\Delta C_{\mathrm{T}}}$, where $\Delta \mathrm{C}_{\mathrm{T}}=\left(\mathrm{C}_{\mathrm{TmiRNA}}-\mathrm{C}_{\mathrm{TU} \text { RNA }}\right)$ (Schmittgen et al. 2004). PCRs were performed in triplicate using iCycler (Bio-Rad) with SYBR Green PCR Master Mix
(Applied Biosystems, Foster City, CA, USA) as follows: $95^{\circ} \mathrm{C}$ for $10 \mathrm{~min}$ and 40 cycles $\left(95^{\circ} \mathrm{C}\right.$ for $15 \mathrm{~s}$ and $60^{\circ} \mathrm{C}$ for $1 \mathrm{~min}$ ). A dissociation curve was run after each PCR in order to verify amplification specificity. The miRNAs analyzed included miR-221 and -222 and $-181 \mathrm{~b}-1$ precursors. The primers used were as follows. Human miR-221 forward 5'-TTCGTTAGGCAACAGCTACATT-3', human miR-221 reverse $5^{\prime}$-GAACATGTTTCCAGGTAGCC-3'; human miR-222 forward 5'-GCTGCTGGAAGGTGTAGGTA-3', human miR-222 reverse $5^{\prime}$ GATGCCATCAGAGACCCAGT-3'; human miR181b-1 forward 5'-ATCAACATTCATTGCTGTCGG-3', human miR-181b-1 reverse 5'-ATTGTTCAGTGAGCTTGTCCA-3'; rat miR-221 forward 5'TTTGTTAGGCAACAGCTACATT- $3^{\prime}$, rat miR221 reverse $5^{\prime}$-AGAAATGCTTCCAGGTAGCC-3'; rat miR-181b-1 forward $5^{\prime}$-ATCAACATTCATTGCTGTCGG-3', rat miR-181b-1 reverse $5^{\prime}$ ATTGTTCAGTGAGCTTTTCTA-3'; mouse miR221 forward 5'-TTTGTTAGGCAACAGCTAC-3', mouse miR-221 reverse $5^{\prime}$-TTCCAGGTAGCCTGAAAC-3'; mouse miR-181b-1 forward $5^{\prime}$-AACATTCAACGCTGTCGGT-3', mouse miR-181b-1 reverse 5'-TTGCATTCATTGTTCAGTGAG-3'. Finally, primers for human, rat and mouse U6 were $5^{\prime}$ CTCGCTTCGGCAGCACA-3' for forward and 5'-AACGCTTCACGAATTTGCGT-3' for reverse.

\section{Cell culture}

The human thyroid carcinoma cell lines TPC-1 (Tanaka et al. 1987), NPA (Pang et al. 1989), B-CPAP (Fabien et al. 1994) and FB-2 (Basolo et al. 2002) were grown in Dulbecco's modified Eagles' medium (Gibco Laboratories, Carlsbad, CA, USA) containing 10\% fetal calf serum (Gibco Laboratories), glutamine (Gibco Laboratories) and ampicillin/streptomycin (Gibco Laboratories) in a $5 \% \mathrm{CO}_{2}$ atmosphere. $\mathrm{PC} \mathrm{Cl} 3$ cell line derived from Fischer rat thyroid (Fusco et al. 1987) was cultured in modified F12 medium supplemented with 5\% calf serum (Gibco Laboratories) and six growth factors (thyrotropic hormone, hydrocortisone, insulin, transferrin, somatostatin and glycylhistidyl-lysine (Sigma, St Louis, MO, USA)). PC CL 3 infected with several oncogenes PC v-ras-Ki, PC v-ras-Ha, PC v-raf, PC v-mos (Fusco et al. 1987), PC PyMLV (Berlingieri et al. 1988), PC E1A-raf (Berlingieri et al. 1993) and PC RET/PTC (Santoro et al. 1993) were cultured in the same medium as PC CL 3 but in the absence of the six growth factors. 


\section{Transfection assay}

2'-O-Me-221-GAAACCCAGCAGACAAUGUAGCUL oligonucleotide and 2'-O-Me-enhanced green fluorescent protein (eGFP)-AAGGCAAGCUGACCCUGAAGUL (as control) were used in the antisense experiments. All 2'-O-methyl oligonucleotides were synthesized by Fidelity Systems, Inc. (Gaithersburg, MD, USA) as previously described (Meister et al. 2004) and were used at $200 \mathrm{nM}$ concentration. NPA cells were plated at $1 \times 10^{5}$ cells per well, in six-well plates, with three replicate wells for each condition, transfected with siPORT neoFX (Ambion, Austin, TX, USA) according to the manufacturer's protocols, and counted by a Vi-Cell (Beckman Coulter, Inc., Fullerton, CA, USA) at 24, 48, 72 and $96 \mathrm{~h}$ post-transfection.

\section{Plasmid constructs and cell colony-forming assay}

miR-221 expression plasmid was constructed by cloning in sense orientation a genomic sequence including miR-221 in BglII/HindIII cloning sites of a mammalian expression vector, pRS-GFP-Neo (OligoEngine, Seattle, WA, USA). Primers used were as follows: forward 5'-AAAGATCTCCCAGCATTTCTGACTG- $3^{\prime}$ and reverse $5^{\prime}$-AAAAGCTTAGACCATTTGGGTGAAAT- $3^{\prime}$. The expression of pRS-GFPNeo-221 was assessed by northern blot as described, and western blotting for the GFP levels was used to show the equal efficiency of transfection with the pRS-GFP-Neo and pRS-GFP-Neo-221 constructs. NPA cells, plated at a density of $90 \%$ in $100 \mathrm{~mm}$ dishes, were transfected with $5 \mu \mathrm{g}$ pRS-GFP-Neo221 or pRS-GFP-Neo. After $24 \mathrm{~h}$ the antibiotic geneticin (G418; Gibco) was added. Two weeks after the onset of drug selection, the cells were fixed and stained with crystal violet $(0.1 \%$ crystal violet in $20 \%$ methanol).

\section{Results}

\section{miRNA expression profile of PTC versus normal thyroid}

We used a miRNACHIP microarray (Liu et al. 2004) to evaluate the miRNA expression profile of 30

Table 1 miRNAs differentially expressed between human PTCs and normal thyroid tissues

\begin{tabular}{|c|c|c|c|c|c|c|c|c|c|}
\hline \multirow[b]{3}{*}{ miRNA name } & \multirow[b]{3}{*}{$P$} & \multirow[b]{3}{*}{ Chr. map } & \multicolumn{3}{|c|}{ Normal thyroid } & \multicolumn{3}{|c|}{ PTC } & \multirow[b]{3}{*}{ Fold change } \\
\hline & & & \multirow{2}{*}{$\begin{array}{l}\text { Median } \\
\text { Normalized }\end{array}$} & \multicolumn{2}{|c|}{ Range } & \multirow{2}{*}{$\frac{\text { Median }}{\text { Normalized }}$} & \multicolumn{2}{|c|}{ Range } & \\
\hline & & & & Min. & Max. & & Min. & Max. & \\
\hline miR-125b-1 & 0.0471 & $11 q 24.1$ & 7.41 & 3.28 & 13.80 & 12.30 & 5.04 & 31.26 & 1.66 \\
\hline miR-148 & 0.0466 & $7 p 15$ & 0.89 & 0.62 & 1.17 & 0.70 & 0.39 & 1.40 & -1.27 \\
\hline miR-224 & 0.0415 & Xq28 & 3.59 & 1.79 & 8.34 & 6.42 & 2.32 & 16.52 & 1.79 \\
\hline miR-125b-2 & 0.0364 & $21 q 11.2$ & 5.52 & 2.86 & 9.07 & 8.59 & 4.61 & 23.25 & 1.56 \\
\hline let-7f-1 & 0.0299 & $9 q 22.2$ & 0.96 & 0.72 & 1.34 & 0.79 & 0.56 & 1.19 & -1.21 \\
\hline miR-202 & 0.0275 & $1 q 26.3$ & 0.78 & 0.57 & 1.14 & 0.98 & 0.67 & 1.50 & 1.25 \\
\hline miR-196-2 & 0.0224 & $12 q 13$ & 0.84 & 0.57 & 1.48 & 1.16 & 0.66 & 2.13 & 1.38 \\
\hline miR-034 & 0.0143 & $1 p 36.22$ & 0.81 & 0.57 & 1.10 & 1.03 & 0.73 & 1.46 & 1.27 \\
\hline miR-221 & 0.0143 & Xp11.3 & 4.91 & 1.82 & 14.17 & 17.97 & 1.03 & 137.63 & 3.66 \\
\hline miR-151 & 0.00935 & $8 q 24.3$ & 0.99 & 0.67 & 1.50 & 0.69 & 0.47 & 1.07 & -1.42 \\
\hline miR-015-b & 0.00879 & $3 q 26.1$ & 0.90 & 0.82 & 1.08 & 0.75 & 0.44 & 1.32 & -1.20 \\
\hline miR-142-as & 0.00535 & $17 q 23$ & 0.90 & 0.71 & 1.41 & 0.62 & 0.36 & 0.99 & -1.46 \\
\hline miR-220 & 0.00435 & Xq25 & 1.16 & 0.95 & 1.54 & 2.72 & 0.59 & 17.58 & 2.35 \\
\hline miR-222 & 0.00256 & Xp11.3 & 3.34 & 1.51 & 8.80 & 15.46 & 1.27 & 87.92 & 4.63 \\
\hline $\operatorname{miR}-125 a$ & 0.00207 & $19 q 13.4$ & 2.01 & 1.10 & 2.84 & 3.39 & 1.72 & 6.15 & 1.69 \\
\hline miR-199a-1 & 0.00178 & 19p13.2 & 0.99 & 0.79 & 1.39 & 0.75 & 0.42 & 1.05 & -1.32 \\
\hline miR-140-as & 0.000948 & $16 q 22.1$ & 1.05 & 0.83 & 1.35 & 0.79 & 0.54 & 1.28 & -1.33 \\
\hline miR-213 & 0.000595 & 1q31.3-q32.1 & 7.18 & 3.58 & 9.66 & 15.30 & 10.28 & 32.74 & 2.13 \\
\hline miR-200a & 0.00026 & $1 p 36.3$ & 0.85 & 0.59 & 1.08 & 1.20 & 0.89 & 1.62 & 1.42 \\
\hline miR-181a & 0.000247 & $9 q 33.1-34.13$ & 2.26 & 1.42 & 3.22 & 4.21 & 1.89 & 10.21 & 1.87 \\
\hline $\mathrm{miR}-181 \mathrm{c}$ & ${ }^{\mathrm{a}} 7.88 \mathrm{E}-05$ & $19 p 13.3$ & 1.13 & 0.84 & 1.60 & 1.97 & 0.89 & 4.84 & 1.74 \\
\hline $\mathrm{miR}-181 \mathrm{~b}$ & ${ }^{b} 3.68 E-05$ & $1 q 31.2-q 32.1$ & 1.50 & 1.22 & 2.30 & 4.45 & 1.69 & 8.43 & 2.97 \\
\hline
\end{tabular}

\footnotetext{
a exponential annotation for 0.0000788

bexponential annotation for 0.0000368

Chr. map, chromosomal map
} 


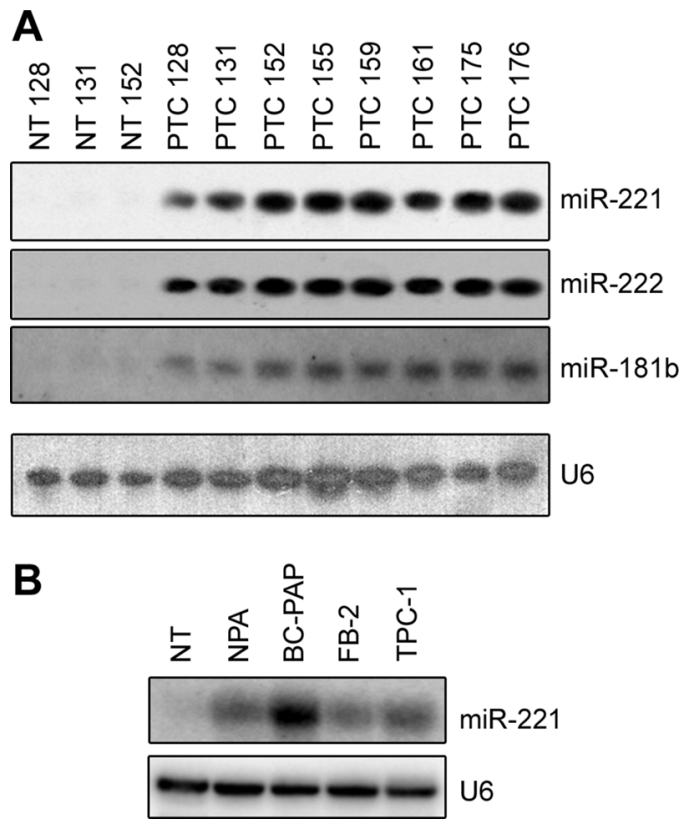

Figure 1 (A) Northern blot analysis performed on human PTC samples. The probe used corresponds to the complementary sequence of mature miR-221, -222 and $-181 b$. The U6 probe was used for normalization of expression levels in the different samples. NT, normal thyroid tissues. (B) Northern blot analysis of miR-221 in a panel of four PTC cell lines of human origin.

PTCs and ten normal thyroid tissues. The normal thyroid samples were all matched with their corresponding carcinoma samples. By applying ANOVA analysis, we obtained a list of differentially expressed miRNAs $(P<0.05)$ between normal and neoplastic thyroids (Table 1). Altered level of the corresponding precursors were observed in some cases (data not shown).

Five miRNAs were overexpressed with a fold change equal to or higher than two in the neoplastic tissues vs the normal ones: they were miR-221, -222 , $-213,-220$ and $-181 \mathrm{~b}$. In contrast, none of the analyzed miRNAs showed a more than twofold reduction in its expression in the tumor samples. We then decided to concentrate on three of these miRNA for further studies since they showed the highest fold change. To confirm these results we performed northern blot analysis on a limited number of PTC samples using probes corresponding to miR-221, -222 and -181b (Fig. 1A). Northern blots confirmed the results obtained by microarray analysis, and in many cases the differences in miRNA expression between normal and neoplastic thyroid samples were even stronger than those anticipated by the microarray screen. In fact, as shown in Fig. 1A, miR-221, -222 and -181 b were abundantly expressed in all the eight PTCs examined, whereas their expression was only weakly detectable in the normal thyroid tissues. Northern blot analysis of four cell lines deriving from human PTC also revealed a higher miR-221 expression in comparison with the normal thyroid tissue (Fig. 1B). Next, we used quantitative RT-PCR to evaluate the expression of miR-221, -222 and $-181 \mathrm{~b}-1$ precursors in a panel of eight thyroid follicular adenomas (FAs) and 39 PTCs, different from those analyzed by miRNACHIP microarray. Figure 2 shows that miR-221, -222 and $-181 b-1$ precursors were overexpressed in almost all the carcinoma samples, being very high in some of them (miR-221 fold change: up to 74fold with an average of 13.5; miR-222 fold change: up to 60 -fold with an average of 13.7 ; miR-181b-1 fold change: up to 58.8 -fold with an average of 13.48). These results confirmed that the increase in miR-221, -222 and $-181 \mathrm{~b}$ expression level represents a signature of the human PTC.

Interestingly, no miR-221 and -222 precursor overexpression was observed in the FA samples analyzed. In contrast, as shown in Fig. 2C, a modest increase in miR-181b-1 precursor expression was also detected in these FA samples (miR-181b-1 fold change: up to 8.56 with an average of 2.26).

\section{Analysis of miRNA expression in thyroid FNABs}

FNAB may be a useful tool in the pre-operative diagnosis of thyroid neoplasias in cases in which the material is too low to set up an immunohistochemical assay. To evaluate the applicability of miR-221, -222 and $-181 \mathrm{~b}$ gene expression analysis to FNAB samples, we studied eight cases of PTC. Normal thyroid cells, used as controls, were obtained from FNABs of thyroids carrying nonneoplastic nodules. The cytological specimens were analyzed for miR-221, -222 and $-181 \mathrm{~b}$ expression by quantitative RT-PCR on their precursors. A much higher expression of these three miRNAs was detected in seven out of eight analyzed carcinoma samples with respect to the normal thyroid cells (Fig. 3).

\section{Overexpression of $\mathrm{miR}-221$ and $-181 \mathrm{~b}$ in experimental rat and mouse models of thyroid carcinogenesis}

Rat thyroid differentiated follicular cells, $\mathrm{PC} \mathrm{Cl} 3$ cells, have been previously transformed with several viral and cellular oncogenes. Some of them, 

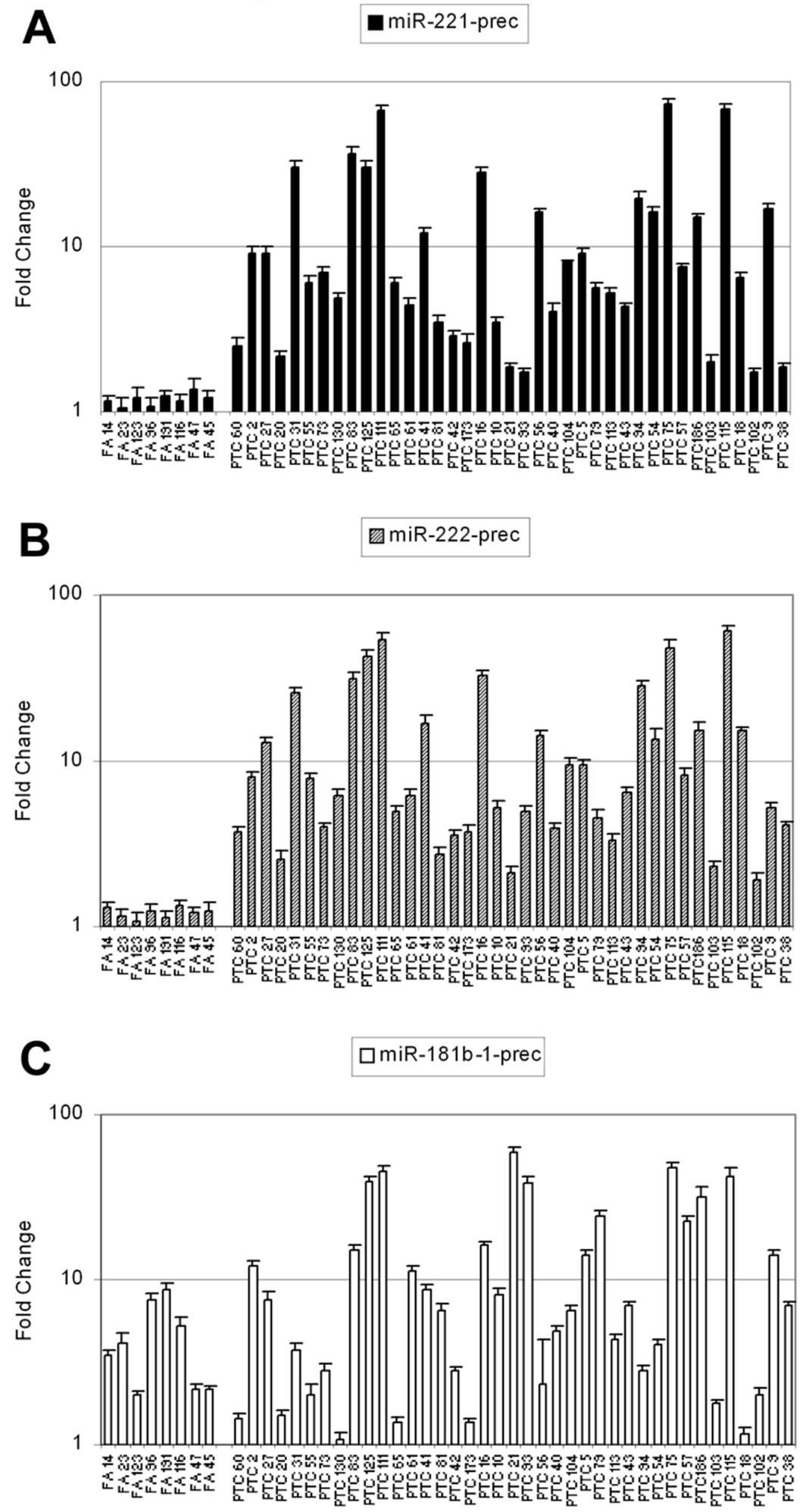

Figure 2 Quantitative RT-PCR analysis was performed on a panel of FAs and PTC samples of human thyroid origin. The fold change values indicate the relative change in the expression levels between tumor samples and the respective normal thyroid tissues deriving from each patient, assuming that the value of each normal sample was equal to 1. The expression of $(A)$ miR-221, (B) -222 and (C) -181b-1 precursors (prec) are shown. 


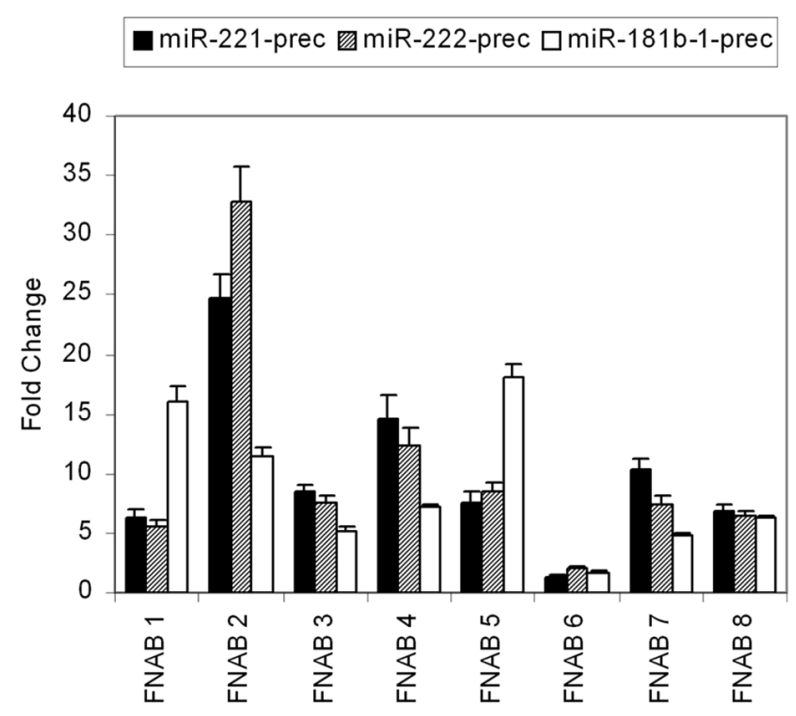

Figure 3 Quantitative RT-PCR analysis of miR-221, -222 and -181b-1 precursors (prec) was performed on human thyroid FNAB samples obtained from patients suspected to have a thyroid cancer and, subsequently, confirmed to have a PTC. Normal thyroid cells, obtained from FNAB of thyroids carrying non-neoplastic nodules, were used as controls. The fold change values indicate the relative change in the expression levels between tumor samples and the normal control, assuming that the value of the normal sample was equal to 1 . FNAB 1-8, FNABs from different patients.

such as RET/PTC, v-raf and v-ras-Ha correspond to the oncogenes frequently activated in human PTCs. These cell lines were analyzed for the expression of miR-221 and $-181 \mathrm{~b}$ by quantitative RT-PCR on their precursors. Figure 4A shows that miR-221 and $-181 \mathrm{~b}-1$ precursors were not detectable in the normal $\mathrm{PC} \mathrm{Cl} 3$ cells, whereas they were abundantly expressed in the $\mathrm{PC} \mathrm{Cl} 3$ cells transformed by v-rasHa, v-ras-Ki, v-raf, RET/PTC1, RET/PTC3, E1AAbl, E1A-raf, PyPMLV and v-mos. The miR-221 expression was particularly high in the PC v-mos cell line. Northern blot, shown in Fig. 4B, essentially confirmed the miR-221 results obtained by quantitative RT-PCR. Similar results were obtained when miR-222 expression was evaluated (data not shown).

PTCs developing in transgenic animal lines expressing tyrosine kinase receptor TRK) (thyroglobulin (Tg)-TRK) (Russel et al. 2000), RET/ PTC3 (Tg-RET/PTC3) (Powell et al. 1998) and HPV E7 (Tg-E7) (Ledent et al. 1995) oncogenes under the transcriptional control of the Tg promoter have also been analyzed for miR-221 and -181b-1 precursor expression by quantitative RT-PCR analysis. As shown in Fig. 4C, elevated specific miR-221 and -181b-1 precursor RNA levels were observed in the thyroid carcinomas samples, whereas they were expressed at low levels in normal mouse thyroid tissues. Similar results were obtained for miR-222 (data not shown). Therefore, miR-221, -222 and $-181 \mathrm{~b}$ were also overexpressed in experimental models of thyroid carcinogenesis.

\section{Overexpression of miR-221 affects the growth of thyroid cancer cell lines}

The aberrant expression of miR-221, -222 and $-181 b$ in PTCs prompted us to investigate whether their overexpression could be a causative event of the thyroid cell proliferation. To this purpose, we selected miR-221 for functional studies starting with a colony-forming assay on a human PTC cell line (NPA). As shown in Fig. 5A, transfection with miR-221 gave rise to a higher number (>twofold) of colonies in comparison with the same cells transfected with the empty vector. Northern blot analysis confirmed the overexpression of miR-221 in the NPA transfected cells (data not shown).

\section{Blocking miR-221 expression inhibits thyroid carcinoma cell growth}

In order to investigate the role of miR-221 overexpression in the growth of thyroid neoplastic cells, we blocked the miR-221 function by transfecting the NPA cells with modified antisense oligonucleotides for the miR-221. As shown in Fig. 5B, no miR-221 RNA was detected in the NPA cells treated with the antisense oligonucleotides (2'-OMe-221), while it was present in those treated with the control oligonucleotides (2'-O-Me-eGFP). A significant reduction of NPA cell number treated with the antisense oligo compared with the control cells was observed at 72 and $96 \mathrm{~h}$ after oligonucleotide transfection (Fig. 5C). These results suggest that miR-221 overexpression has an important role in thyroid carcinoma cell proliferation.

\section{Discussion}

miRNAs mediate a recently recognized form of translational inhibition that alters the levels of critical proteins, thereby providing a mechanism for spatio-temporal control of developmental and homeostatic events across a wide range of plants and animals (Bartel 2004, Ambros 2004). Because abnormal proliferation and/or apoptosis are a hallmark of human cancers, it seems possible that miRNA expression patterns might denote the 


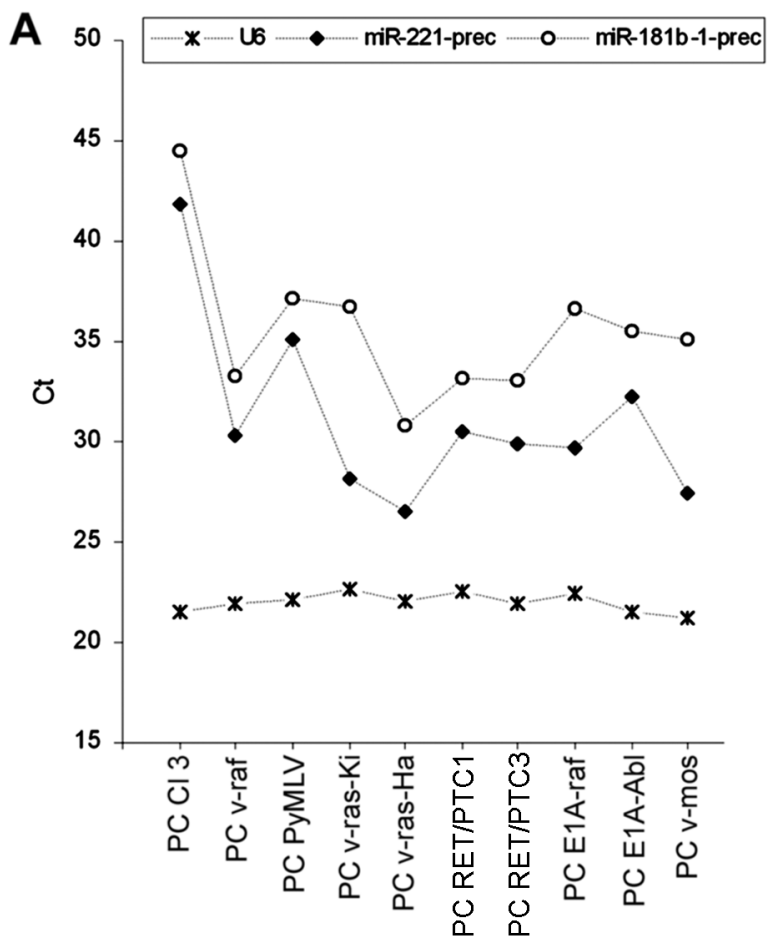

B

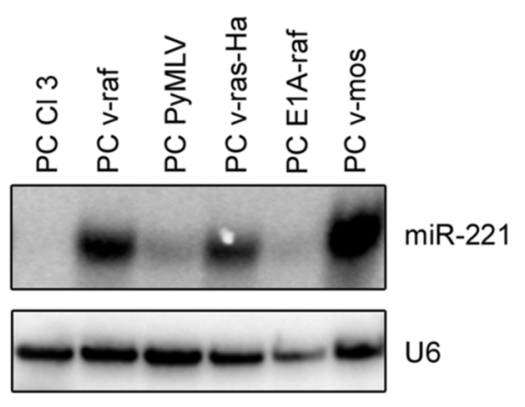

C

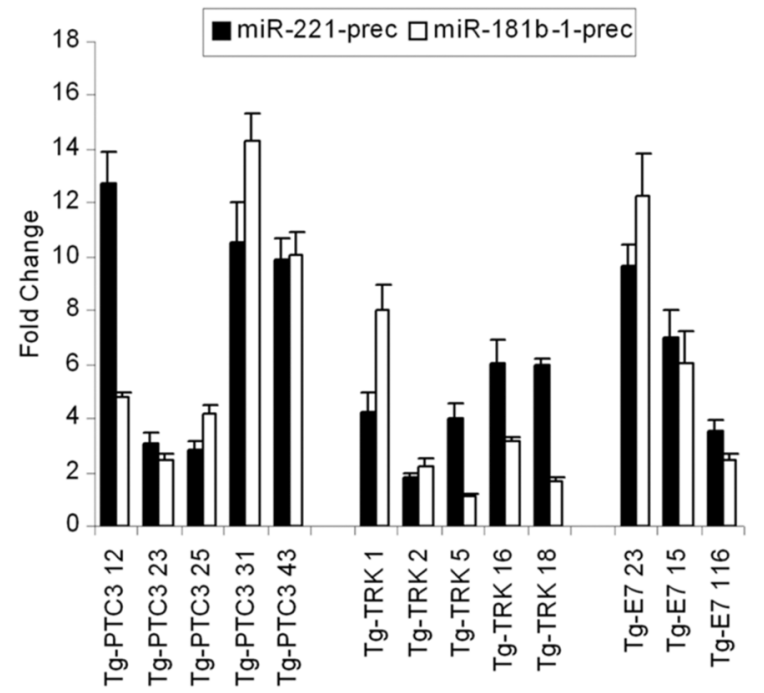

malignant state. Indeed, altered expression of a few miRNAs has been found in some tumor types, and recent studies have shown that altered expression of specific miRNA genes contributes to the initiation and progression of cancer (Calin et al. 2002, 2004a,b, 2005, Lagos-Quintana et al. 2003, McManus 2003, Michael et al. 2003, Metzler et al. 2004, Takamizawa et al. 2004, Eis et al. 2005, Gregory \& Shiekhattar 2005, Iorio et al. 2005, Johnson et al. 2005). Therefore, miRNA expression profiles offer the potential to inform cancer classification, diagnosis and prognosis.

Thyroid neoplasms represent an excellent model for studying the process of cell transformation since they include a broad spectrum of histotypes showing different degrees of malignancy (Hedinger et al. 1989, Wynford-Thomas 1997). In our study, we have analyzed, by miRNACHIP microarray, 30 PTCs and 10 normal thyroid samples to identify miRNAs whose expression is significantly deregulated in cancer. We have indeed identified about 30 miRNAs significantly deregulated and at least five of them whose expression was highly upregulated. These results leave few doubts that aberrant expression of miRNAs is common in human thyroid cancers; however, additional experiments are necessary to conclusively demonstrate that miRNA upregulation functions in human thyroid carcinogenesis.

Interestingly, we have found miRNAs significantly upregulated in PTC samples, whereas no miRNA has been found downregulated with a fold

Figure 4 miR-221 and -181b-1 precursor (prec) expression in experimental models of thyroid carcinogenesis. A panel of rat thyroid cell lines was tested for miR-221 and -181b-1 precursor expression. (A) Quantitative RT-PCR analysis: RNA

transcription levels of $\mathrm{U} 6$ reference gene (internal control) and miR-221 and -181b-1 precursors are expressed as absolute Ct values (Ct represents the amplification cycle number in which fluorescence levels are first detected for a sample). The same amount of RNA for each sample was used as a template to amplify U6, miR-221 and 181b-1 genes. (B) Northern blot analysis using a probe corresponding to complementary sequences of the mature miR-221. The U6 probe was used for normalization of expression levels in the different samples. (C) Quantitative RT-PCR analysis performed on a panel of experimental mouse models of thyroid carcinogenesis. Normal mouse thyroid tissues were used as controls. The fold change values indicate the relative change in the expression levels between tumor samples and normal thyroid samples, assuming that the value of each normal sample was equal to 1. Tg-PTC3, $\mathrm{Tg}$-TRK and Tg-E7 are transgenic mouse lines expressing respectively RET/PTC3, TRK and HPV E7 oncogenes under the transcriptional control of the $\mathrm{Tg}$ promoter. 
A

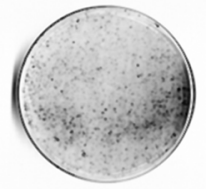

NPA-pRS-GFP-Neo

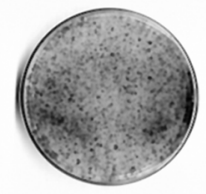

NPA-pRS-GFP-Neo-221
B

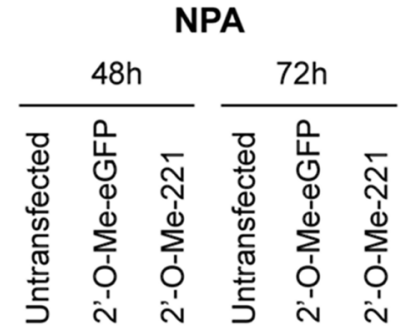

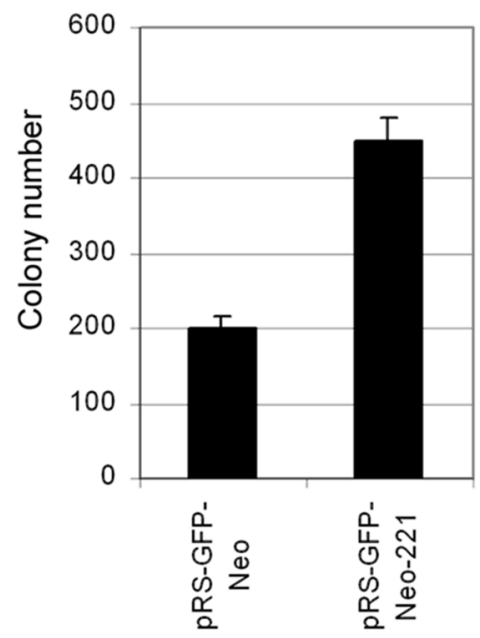

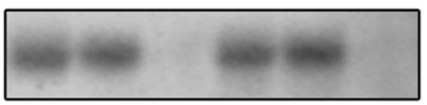

$\operatorname{miR}-221$

U6

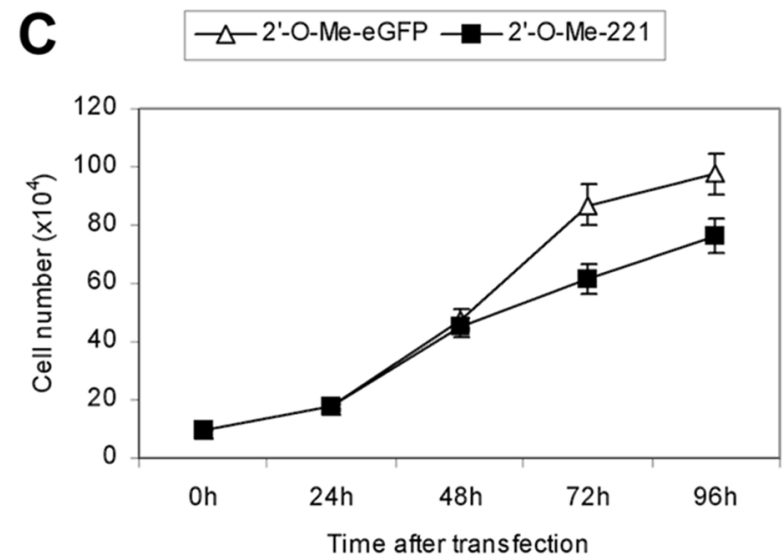

Figure 5 (A) Colony-forming assay experiment performed on NPA cells transfected with a vector expressing miR-221 (pRS-GFP-Neo-221) under the transcriptional control of the $\mathrm{H} 1$ gene promoter. The empty vector (pRS-GFP-Neo) was used as a control. The reported results are the mean of two experiments and error bars show S.D. (B) Northern blot assessing the effective downregulation of the endogenous miR-221 RNA, in NPA cells, after the transfection with 2'-O-methyl oligonucleotides corresponding to the complementary sequence of miR-221 (2'-O-Me-221). 2'-O-methyl oligonucleotides complementary to the sequence of GFP mRNA (2'-O-Me-eGFP) were used as a control. (C) Cells were counted at 24, 48, 72 and $96 \mathrm{~h}$ post-transfection of 2'-O-Me-221 and 2'-O-Me-eGFP oligonucleotides.

change higher than two. This would therefore suggest that gain- rather than loss-of-function of specific miRNAs is involved in PTC. Interestingly, preliminary data (not shown) on anaplastic thyroid carcinomas (ATCs) showed an opposite result: only a few miRNAs were upregulated (with a very low fold change), whereas several miRNAs were drastically downregulated. In ATCs it is possible that miRNAs might function as tumor suppressor or differentiation genes. This scenario shows some analogies with the other genetic lesions in thyroid carcinogenesis: activation of oncogenes (such as RET/PTC, TRK, B-raf, ras) in PTC, and loss-offunction of the p53 tumor suppressor in ATC.

miR-221, -222 and $-181 \mathrm{~b}$ induction is a constant feature of PTCs. Their upregulation therefore represents a real signature of PTC. Indeed, their upregulation has been validated by northern blot and quantitative RT-PCR on a large number of samples and, as in the case of miR-221, the overexpression may reach up to a 70 -fold increase.

It is worth noting that miR-221 and -222 (both precursors and mature products) in our system showed a very high similar expression pattern. This is consistent with the observation that miR-221 and -222 are clustered on chromosome X (Altuvia et al. 2005) showing, like some other clustered miRNA genes, high similarity in sequence (Bartel 2004) and perhaps they might be transcribed as polycistrons (Bartel 2004, Cullen 2004, Baskerville $\&$ Bartel 2005). Our studies in vivo and in vitro confirmed their upregulation during thyroid cell transformation. In fact, miR-221 expression is completely absent in the normal rat thyroid cell 
line $\mathrm{PC} \mathrm{Cl} 3$ and in mouse normal thyroid tissues, while it is clearly detectable in the corresponding transformed cells and in PTCs developed in TgRET/PTC, Tg-TRK and Tg-E7 mice. The same also occurs for miR-181b. As far as the mechanism underlying miRNA overexpression in PTCs, we can exclude the possibility that gene amplification plays a major role. It is likely that other mechanisms account for the miRNA upregulation during the process of thyroid carcinogenesis.

It is worth noting that miR-221 and -222 are not overexpressed in benign and well-differentiated FAs. These results suggest the measurement of these miRNA levels for a differential diagnosis between benign and malignant thyroid neoplasms. The analysis of a larger number of samples will be required to ascertain the miRNA expression evaluation as a valid tool for the diagnosis of thyroid neoplasias.

One of the aims of our work has also been to investigate a possible role of miR-221 overexpression in thyroid carcinogenesis. To answer this question we have followed two experimental approaches. We have performed a colony assay on a human thyroid carcinoma cell line transfected with a vector overexpressing the miR-221 and found that the number of colonies was significantly higher in the cells overexpressing miR-221. The other approach was based on blocking the miR221 function by antisense oligonucleotides: a significant reduction in the cell growth was observed. Both these experiments therefore point to a role of miR-221 in thyroid carcinoma cell growth. The generation of transgenic mice overexpressing miR-221 under the transcriptional control of a thyroid specific promoter, such as that of the $\mathrm{Tg}$ gene, should give the definitive answer to this question. Experiments aimed at validating a role of miR$181 \mathrm{~b}$ overexpression in thyroid cell growth are also in progress in our laboratories.

miRNAs are known to regulate the expression of genes involved in the control of development, proliferation, apoptosis and stress response (He \& Hannon 2004). In animal cells, single-stranded miRNAs bind to specific target mRNAs through partial complementarity predominantly in the $3^{\prime}$ UTR. The bound mRNAs either remain untranslated, resulting in a decrease of the corresponding protein product, or are degraded by the RNA interference effector complex resulting in a decreased number of transcripts (Bartel 2004). We therefore looked at the predicted targets of the most significantly upregulated miRNAs. We used the most commonly used algorithms TARGETSCAN (Lewis et al. 2003), PICTAR (Krek et al. 2005) and MIRANDA (John et al. 2004) to predict human miRNA gene targets. TARGETSCAN (2003 version) and MIRANDA identified c-KIT as a putative target of miR-221 (also of miR-222 in TARGETSCAN), while PICTAR identified c-KIT as a target of miR-181b. Moreover, it has also been demonstrated that miR-221 and miR-222 are really able to downregulate the level of c-KIT protein (Felli et al. 2005). Our preliminary data, obtained by western blot and immunohistochemistry, seem to indicate that c-KIT protein levels are drastically reduced in PTCs, confirming data published by our group some years ago (Natali et al. 1995).

While this work was in progress, a paper on the expression profile of miRNAs in PTCs has been published (He et al. 2005). Our results are not only confirmatory of these published data, but they also add some more information about the overexpression of these miRNAs in experimental thyroid cell and animal systems and, more importantly, suggest a role of miR-221 in the proliferation of human thyroid carcinoma cells and thus, probably, in the process of thyroid carcinogenesis. On the other hand, our paper has also revealed by quantitative RT-PCR an overexpression in PTC of miR-181b which has not been described previously.

In conclusion, this study has indicated a miRNA signature associated to PTCs and suggests a critical role of miR-221 overexpression in thyroid carcinogenesis.

\section{Acknowledgements}

This work was supported by grants from the Associazione Italiana Ricerca sul Cancro (AIRC), Progetto Strategico Oncologia, Consiglio Nazionale delle Ricerche and the Ministero dell'Università e della Ricerca Scientifica e Tecnologica (MIUR). It was supported by NOGEC (Naples Oncogenomic Center). We thank the Associazione Partenopea per le Ricerche Oncologiche (APRO) for its support. The authors declare that there is no conflict of interest that would prejudice the impartiality of this scientific work.

\section{References}

Altuvia Y, Landgraf P, Lithwick G, Elefant N, Pfeffer S, Aravin A, Brownstein MJ, Tuschl T \& Margalit H 2005 Clustering and conservation patterns of human microRNAs. Nucleic Acids Research 33 2697-2706. 
Ambros V 2004 The functions of animal microRNAs. Nature 431 350-355.

Bartel DP 2004 MicroRNAs: genomics, biogenesis, mechanism, and function. Cell 116 281-297.

Baskerville S \& Bartel DP 2005 Microarray profiling of microRNAs reveals frequent coexpression with neighboring miRNAs and host genes. RNA 11 241-247.

Basolo F, Giannini R, Toniolo A, Casalone R, Nikiforova M, Pacini F, Elisei R, Miccoli P, Berti P, Faviana P et al. 2002 Establishment of a non-tumorigenic papillary thyroid cell line (FB-2) carrying the RET/PTC1 rearrangement. International Journal of Cancer 97 608-614.

Berlingieri MT, Portella G, Grieco M, Santoro M \& Fusco A 1988 Cooperation between the polyomavirus middle$\mathrm{T}$-antigen gene and the human c-myc oncogene in a rat thyroid epithelial differentiated cell line: model of in vitro progression. Molecular and Cellular Biology $\mathbf{8}$ 2261-2266.

Berlingieri MT, Santoro M, Battaglia C, Grieco M \& Fusco A 1993 The adenovirus E1A gene blocks the differentiation of a thyroid epithelial cell line; however, the neoplastic phenotype is achieved only after cooperation with other oncogenes. Oncogene 8 249-255.

Calin GA, Dumitru CD, Shimizu M, Bichi R, Zupo S, Noch E, Aldler H, Rattan S, Keating M, Rai K et al. 2002 Frequent deletions and down-regulation of microRNA genes miR15 and miR16 at 13q14 in chronic lymphocytic leukemia. PNAS 99 15524-15529.

Calin GA, Sevignani C, Dumitru CD, Hyslop T, Noch E, Yendamuri S, Shimizu M, Rattan S, Bullrich F, Negrini M et al. 2004a Human microRNA genes are frequently located at fragile sites and genomic regions involved in cancers. PNAS 101 2999-3004.

Calin GA, Liu CG, Sevignani C, Ferracin M, Felli N, Dumitru CD, Shimizu M, Cimmino A, Zupo S, Dono M et al. $2004 \mathrm{~b}$ MicroRNA profiling reveals distinct signatures in B cell chronic lymphocytic leukemias. PNAS 101 11755-11760.

Calin GA, Ferracin M, Cimmino A, Di Leva G, Shimizu M, Wojcik SE, Iorio MV, Visone R, Sever NI, Fabbri M et al. 2005 A microRNA signature associated with prognosis and progression in chronic lymphocytic leukemia. New England Journal of Medicine 353 1793-1801.

Cullen BR 2004 Transcription and processing of human microRNA precursors. Molecular Cell 16 861-865.

Eis PS, Tam W, Sun L, Chadburn A, Li Z, Gomez MF, Lund E \& Dahlberg JE 2005 Accumulation of miR-155 and BIC RNA in human B cell lymphomas. PNAS 102 3627-3632.

Fabien N, Fusco A, Santoro M, Barbier Y, Dubois PM \& Paulin C 1994 Description of a human papillary thyroid carcinoma cell line. Morphologic study and expression of tumoral markers. Cancer 73 2206-2212.

Felli N, Fontana L, Pelosi E, Botta R, Bonci D, Facchiano F, Liuzzi F, Lulli V, Morsilli O, Santoro S et al. 2005 MicroRNAs 221 and 222 inhibit normal erythropoiesis and erythroleukemic cell growth via kit receptor down-modulation. PNAS 102 18081-18086.
Fusco A, Berlingieri MT, Di Fiore PP, Portella G, Grieco M \& Vecchio G 1987 One- and two-step transformation of rat thyroid epithelial cells by retroviral oncogenes. Molecular and Cellular Biology 7 3365-3370.

Gregory RI \& Shiekhattar R 2005 MicroRNA biogenesis and cancer. Cancer Research 65 3509-3512.

He H, Jazdzewski K, Li W, Liyanarachchi S, Nagy R, Volinia S, Calin GA, Liu CG, Franssila K, Suster S et al. 2005 The role of microRNA genes in papillary thyroid carcinoma. PNAS 102 19075-19080.

He L \& Hannon GJ 2004 MicroRNAs: small RNAs with a big role in gene regulation. Nature Reviews Genetics 5 522-531.

Hedinger C, Williams D \& Sobin LH 1989 The WHO histological classification of thyroid tumours: a commentary on the second edition. Cancer 63 908-911.

Iorio MV, Ferracin M, Liu CG, Veronese A, Spizzo R, Sabbioni S, Magri E, Pedriali M, Fabbri M, Campiglio M et al. 2005 MicroRNA gene expression deregulation in human breast cancer. Cancer Research $\mathbf{6 5}$ 7065-7070.

John B, Enright AJ, Aravin A, Tuschl T, Sander C \& Marks DS 2004 Human MicroRNA targets. PLoS Biology 2 e363.

Johnson SM, Grosshans H, Shingara J, Byrom M, Jarvis R, Cheng A, Labourier E, Reinert KL, Brown D \& Slack FJ 2005 RAS is regulated by the let-7 microRNA family. Cell 120 635-647.

Krek A, Grun D, Poy MN, Wolf R, Rosenberg L, Epstein EJ, MacMenamin P, da Piedade I, Gunsalus KC, Stoffel $\mathrm{M}$ et al. 2005 Combinatorial microRNA target predictions. Nature Genetics 37 495-500.

Lagos-Quintana M, Rauhut R, Meyer J, Borkhardt A \& Tuschl T 2003 New microRNAs from mouse and human. RNA 9 175-179.

Ledent C, Marcotte A, Dumont JE, Vassart G \& Parmentier M 1995 Differentiated carcinomas develop as a consequence of the thyroid specific expression of a thyroglobulin-human papillomavirus type $16 \mathrm{E} 7$ transgene. Oncogene 10 1789-1797.

Lewis BP, Shih IH, Jones-Rhoades MW, Bartel DP \& Burge CB 2003 Prediction of mammalian microRNA targets. Cell 115 787-798.

Liang RQ, Li W, Li Y, Tan CY, Li JX, Jin YX \& Ruan KC 2005 An oligonucleotide microarray for microRNA expression analysis based on labeling RNA with quantum dot and nanogold probe. Nucleic Acids Research 33 e17.

Liu CG, Calin GA, Meloon B, Gamliel N, Sevignani C, Ferracin M, Dumitru CD, Shimizu M, Zupo S, Dono M et al. 2004 An oligonucleotide microchip for genomewide microRNA profiling in human and mouse tissues. PNAS 101 9740-9744.

McManus MT 2003 MicroRNAs and cancer. Seminars in Cancer Biology 13 253-258.

Meister G, Landthaler M, Dorsett Y \& Tuschl T 2004 Sequence-specific inhibition of microRNA- and siRNAinduced RNA silencing. RNA $10544-550$. 
Metzler M, Wilda M, Busch K, Viehmann S \& Borkhardt A 2004 High expression of precursor microRNA-155/BIC RNA in children with Burkitt lymphoma. Genes, Chromosomes and Cancer 39 167-169.

Michael MZ, O'Connor SM, van Holst Pellekaan NG, Young GP \& James RJ 2003 Reduced accumulation of specific microRNAs in colorectal neoplasia. Molecular Cancer Research 1 882-891.

Natali PG, Berlingieri MT, Nicotra MR, Fusco A, Santoro E, Bigotti A \& Vecchio G 1995 Transformation of thyroid epithelium is associated with loss of c-kit receptor. Cancer Research 55 1787-1791.

Nelson PT, Baldwin DA, Scearce LM, Oberholtzer JC, Tobias JW \& Mourelatos Z 2004 Microarray-based, high-throughput gene expression profiling of microRNAs. Nature Methods 1 155-161.

Pang XP, Hershman JM, Chung M \& Pekary AE 1989 Characterization of tumor necrosis factor-alpha receptors in human and rat thyroid cells and regulation of the receptors by thyrotropin. Endocrinology 125 1783-1788.

Pillai RS 2005 MicroRNA function: multiple mechanisms for a tiny RNA? RNA 11 1753-1761.

Powell DJ Jr, Russell J, Nibu K, Li G, Rhee E, Liao M, Goldstein M, Keane WM, Santoro M, Fusco A et al. 1998 The RET/PTC3 oncogene: metastatic solid-type papillary carcinomas in murine thyroids. Cancer Research 58 5523-5528.

Rhoades MW, Reinhart BJ, Lim LP, Burge CB, Bartel B \& Bartel DP 2002 Prediction of plant microRNA targets. Cell 110 513-520.

Russell JP, Powell DJ, Cunnane M, Greco A, Portella G, Santoro M, Fusco A \& Rothstein JL 2000 The TRK-T1 fusion protein induces neoplastic transformation of thyroid epithelium. Oncogene 19 5729-5735.

Santoro M, Melillo RM, Berlingieri MT, Grieco M, Vecchio G \& Fusco A 1993 The TRK and RET tyrosine-kinase oncogenes cooperate with ras in the neoplastic transformation of a rat thyroid epithelial cell line. Cell Growth and Differentiation 4 77-84.

Schmittgen TD, Jiang J, Liu Q \& Yang L 2004 A highthroughput method to monitor the expression of microRNA precursors. Nucleic Acids Research 32 e43.

Sempere LF, Freemantle S, Pitha-Rowe I, Moss E, Dmitrovsky E \& Ambros V 2004 Expression profiling of mammalian microRNAs uncovers a subset of brainexpressed microRNAs with possible roles in murine and human neuronal differentiation. Genome Biology 5 R13.

Takamizawa J, Konishi H, Yanagisawa K, Tomida S, Osada H, Endoh H, Harano T, Yatabe Y, Nagino M, Nimura Y et al. 2004 Reduced expression of the let-7 microRNAs in human lung cancers in association with shortened postoperative survival. Cancer Research 64 3753-3756.

Tanaka J, Ogura T, Sato H \& Datano M 1987 Establishment and biological characterization of an in vitro human cytomegalovirus latency model. Virology 161 62-72.

Tang G, Reinhart BJ, Bartel DP \& Zamore PD 2003 A biochemical framework for RNA silencing in plants. Genes and Development 17 49-63.

Troncone G, Fulciniti F, Zeppa P, Vetrani A, Caleo A, Palombini L 2000 Cyclin-dependent kinase inhibitor p27(Kip1) expression in thyroid cells obtained by fineneedle aspiration biopsy: a preliminary report. Diagnostic Cytopathology 23 77-81.

Wynford-Thomas D 1997 Origin and progression of thyroid epithelial tumours. Cellular and molecular mechanisms. Hormone Research 47 145-157.

Zeppa P, Vetrani A, Marino M, Fulciniti F, Boschi R, deRosa G \& Palombini L 1990 Fine needle aspiration of medullary thyroid carcinoma: a review of 18 cases. Cytopathology 1 35-44. 